\title{
COMPARATIVE STUDY BETWEEN NASAL PACKING WITH CARBOXY METHYL CELLULOSE AND LATEX GLOVED MEROCEL IN THE SAME PATIENT AFTER FUNCTIONAL ENDOSCOPIC SINONASAL SURGERY
}

By

\section{Mohammed Abd Al-Fattah Al-Tawy, Ayman Abd Al-Aziz Al-Shahally and Ahmed Mohammed Al-Didamouny}

\author{
Otorhinolaryngology, Faculty of Medicine, Al-Azhar Universtiy
}

E-mail: doctooooor15@gmail.com

\begin{abstract}
Background: Nasal packing after functional endoscopic sinus surgery (FESS) is used as a standard procedure to control the postoperative bleeding, promote the mucosal healing and to prevent synechiae formation, but traditional non-resorbable packs have several disadvantages. The optimum solution to minimize these disadvantages may be accomplished using the new biodegradable packs.

Objectives: This study was done to compare between the effect of carboxy methyl cellulose (CMC) foam nasal pack and latex gloved merocel (LGM) nasal pack in the same patient after FESS regarding the prevention of postoperative bleeding, pain and synechiae formation.

Patients and Methods: A prospective, randomized, single-blinded controlled study was performed in 35 patients with bilateral chronic rhinosinusitis who were collected from ENT outpatient clinic of Al-Hussein University Hospital from Feb. 2019 to Nov. 2019. All patients underwent bilateral FESS by a single surgeon. At the end of the operation, each patient was packed with dissolvable CMC foam nasal pack in one nasal cavity and latex gloved merocel nasal pack in the other side. The hemostatic effect of the CMC foam and latex gloved merocel was assessed during the recovery period. Pain levels were recorded by the patients on a visual analogue scale 2, 6, 12 and 24 hours after surgery and at the time of packing removal. The effectiveness of prevention of synechiae formation was assessed endoscopically 4 and 8 weeks after surgery.

Results: There was no statistically significant difference between CMC group and LGM group as regard their effect on control the postoperative bleeding. Only five (14.3\%) of the CMC group had primary postoperative bleeding, and it occurred in three $(8.6 \%)$ of gloved merocel group. The mean level of patient pain was 0.98 (Range: 0-2) in CMC group, but was 1.65 (Range: 1-3) in latex gloved merocel group which is statistically significant. As regarding synechiae formation, the difference between both groups was statistically insignificant at the 4 weeks period] Two (5.7\%) of CMC group and five (14.3\%) of LGM group developed a synechiae [and statistically significant at the 8 weeks period] three $(8.6 \%)$ of CMC group and nine (25.7\%) of gloved merocel group developed synechiae].
\end{abstract}

Conclusion: Dissolvable CMC foam nasal pack was associated with very low levels of localized pain, and with low levels of postoperative bleeding and synechia formation.

Keywords: Endoscopic sinus surgery, Carboxymethyl cellulose, Merocel, Resorbable, Nasal synechia, Nasal packing, Nasal complications. 


\section{INTRODUCTION}

Chronic rhinosinusitis is a common disease that results in nasal obstruction, rhinorrhea, cough, facial pain, and headache associated sometimes with hyposmia. The long-term sinonasal consequences range from broad sinonasal mucosal thickening to the formation of nasal polyps. Medical therapies including decongestants, antihistamines, topical or oral steroids, systemic antibiotics are often ineffective making surgery necessary. Generally, functional endoscopic sinus surgery (FESS) is the gold standard for removal of sinonasal polyps and excessive mucous, opening of natural drainage channels, and restoration of normal nasal airflow function (Hajosch et al., 2010). FESS has several advantages and allows complete exploration of all paranasal sinus areas, many sinus surgeons place packing or hemostatic agents in the nose at the conclusion of the surgery to control postoperative bleedings, leaving no scar tissue and only mild discomfort, despite these advantages, scarring and reobstruction external of the ostiomeatal complex can impair postoperative recovery (Mira et al., 2009). Intraoperative and postoperative hemorrhage are common complications in FESS. Nasal biomaterials have been designed to address this problem through enzymatic activation of the coagulation cascade, physical pressure tamponade, or both. In clinical trials, hemostatic performance has been assessed via several different metrics, including patientreported blood loss, weight of blood loss, volume of blood loss, bleeding time, incidence of postoperative hemorrhage, need for repacking, and custom and validated bleeding scales (Hosemann and
Draf, 2013). The purpose of postoperative nasal packing lies in the prevention of adhesions and synechias, an improved and accelerated wound healing and most importantly the control of possible postoperative bleedings (Orlandi et al., 2016). Although biomaterials are often used after FESS to prevent hemorrhage and adhesion formation, it is often at the expense of patient comfort. The ordinary nasal packing exacerbates postoperative nasal obstruction and facial pressure, and its removal is sometimes considered to be more traumatic than the surgery. Absorbable biomaterials have been developed to avoid the need to pull nasal packs and thereby decrease patient pain and discomfort. However, any type of nasal packing inserted after FESS likely contributes to patient discomfort to some degree (Massey and Singh, 2017).

The removal of nasal packings has been described as the most painful part of the whole treatment. Modern nasal packings consist of resorbable materials, which make their removal unnecessary, thus giving the patient more comfort (Valentine et al., 2010 and Murr et al., 2011). CMC gel is vegetable-based polysaccharide foam that actively promotes platelet aggregation upon contact with blood. The CMC gels form viscous dissolvable foam that conforms to the nasal cavities while providing a moist, hydrocolloid physical barrier (Szczygielski et al., 2010).

The aim of the work was to compare between carboxy methyl cellulose foam nasal pack and latex gloved merocel nasal pack as regard postoperative bleeding, pain and synechiae formation for the same 


\section{COMPARATIVE STUDY BETWEEN NASAL PACKING WITH CARBOXY... 575}

patient after functional endoscopic sinus surgery.

\section{PATIENTS AND METHODS}

This prospective, single blinded, randomized, controlled study was carried out on 35 patients (15males and 20 females; mean age 36.26 years; range 19 55) with bilateral chronic rhinosinusitis were collected from the ENT outpatient clinic of Al-Hussein University Hospital between Feb. and Nov. 2019, the diagnosis was established by history taking, clinical, endoscopic and radiological examination.

We included patients who were older than 18 years of age and had bilateral chronic rhinosinusitis without previous history of any nasal surgery. The research was approved by the local ethics committee and informed consents were obtained before the study.

Special sheets were done and designed to record all patients' data including full history taking and symptoms of bilateral chronic rhinosinusitis followed by complete general, ENT examination and investigated by computed tomography on the nose and para nasal sinuses. All patients underwent bilateral functional endoscopic sinus surgery which was performed by the same surgeon and performed under total intra venous anesthesia. After completion of surgery in each patient, one nasal cavity was packed with carboxy methyl cellulose foam according to the manufacturer's instructions (The dressing placed in a syringe is composed of two grams of carboxymethyl cellulose (CMC) dry fibers and forms a viscous gel when mixed with sterile solution as $20 \mathrm{cc}$ of ringers lactate) we may easily place it locally on the bleeding surface only, and the other nasal cavity was packed with fenestrated powder free latex gloved merocel in the floor and another small piece inserted in the middle meatus removed 48 hours after surgery. Removal of carboxy methyl cellulose remnants was done after 48 hours by nasal wash and suction. 


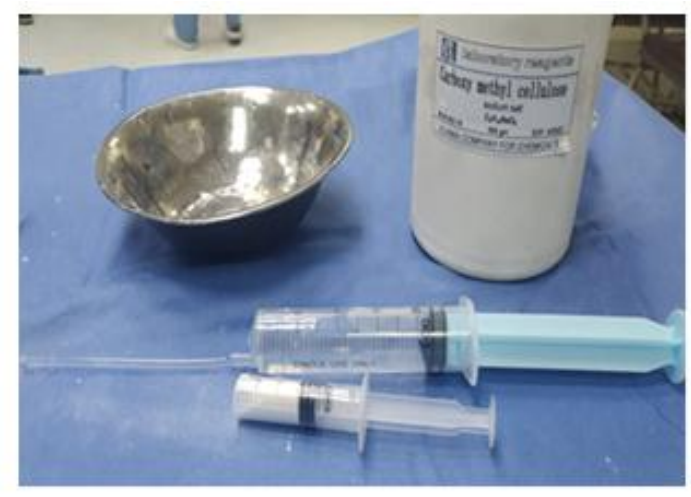

Figure 1. Materials used for preparation of | CMC foam pack.

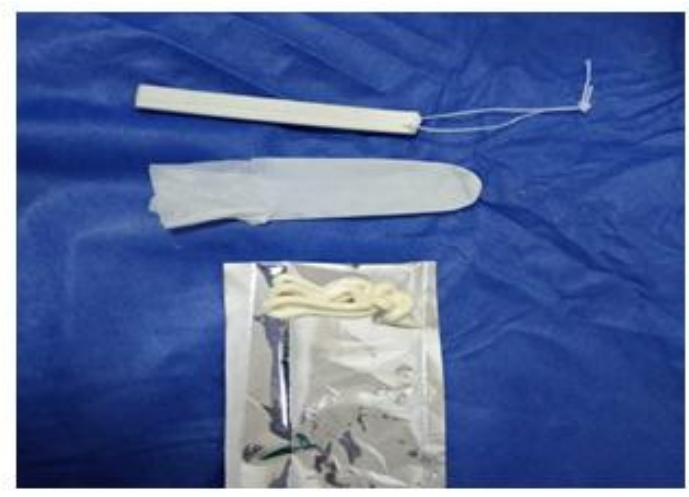

Figure 2. Materials used for preparation of LGM pack.

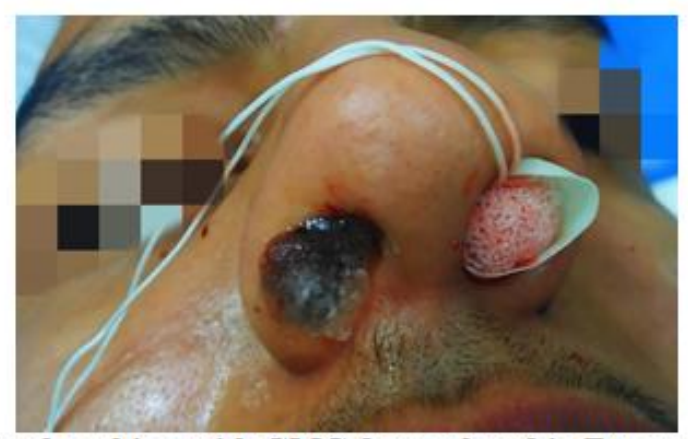

Figure 3. Postoperative nasal packing with CMC foam placed in Rt. nasal cavity and LGM placed in Lt. nasal cavity of the same patient.

The first outcome measured was effectiveness of the pack in bleeding control. The primary hemostatic effect was assessed during the recovery period. Absence of bleeding was marked ' 0 "' and presence of bleeding was marked " 1 ". The second outcome measured was pain of the patient $24 \mathrm{~h}$ after surgery and during pack removal. Before administration of pain relief medications, pain levels were recorded by patients on a visual analogue scale between 0 and 10 , with " 0 " indicating "no pain", and " 10 ", indicating "most severe pain imaginable.'. The third outcome measured was the presence of synechiae at follow-up visits 4 and 8 weeks after surgery. Evaluation was performed bilaterally using 30degree sinoscope. The presence of synechia at any follow-up visit was marked " 1 " and absence was marked " 0 ".

\section{Statistical analysis:}

Recorded data were analyzed using the statistical package for social sciences, version 20.0 (SPSS Inc., Chicago, Illinois, USA). Quantitative data were expressed as mean \pm standard deviation (SD). Qualitative data were expressed as frequency and percentage. The following tests were done:

- Independent-samples t-test of significance was used when comparing between two means.

- Chi-square (x2) test of significance was used in order to compare proportions between qualitative parameters. 


\section{COMPARATIVE STUDY BETWEEN NASAL PACKING WITH CARBOXY... 577}

- The confidence interval was set to $95 \%$ and the margin of error accepted was set to $5 \%$.
- P-value <0.05 was considered significant.

\section{RESULTS}

A total of 35 patient were included in this study, they were 20 female $(57.1 \%)$ and 15 male $(42.9 \%)$ ranging in age from 19 to 55 years with mean of 36.26 years and Standard Deviation 8.02. Diagnosed with bilateral chronic rhinosinusitis underwent bilateral FESS by the same surgeon. Postoperative these patients packed in one nasal cavity with carboxy methyl cellulose foam (CMCF) and in the other nasal cavity with latex gloved merocel (LGM). We compare between both sides regarding the postoperative bleeding, pain and synchiae.
1-Postoperative bleeding: Of the thirty five nasal cavities of the patients packed with $\mathrm{CMCF}$, 5 patient $(14.3 \%)$ had primary postoperative bleeding that required additional, classical packing during the recovery period, while of the other thirty five nasal cavities of the patients packed with LGM, 3 patients had postoperative bleeding $(8.6 \%)$ that required additional packing. The difference between the two groups was not statistically significant $(\mathrm{p}=0.651)$.

Table (1): Comparison between CMCF and LGM among all cases regarding to bleeding postoperatively

\begin{tabular}{|l|l|l|l|l|l|}
\hline \multirow{2}{*}{ Bleeding Groups } & \multicolumn{2}{|l|}{ CMCF $(\mathbf{n}=35)$} & \multicolumn{2}{|l|}{ LGM $(\mathbf{n}=35)$} & \multirow{2}{*}{-value } \\
\cline { 2 - 5 } & No & $\%$ & No & $\%$ & \\
\hline Yes & $\mathbf{5}$ & $\mathbf{1 4 . 3 \%}$ & $\mathbf{3}$ & $\mathbf{8 . 6 \%}$ & \multirow{2}{*}{$\mathbf{0 . 0 5}$} \\
No & $\mathbf{3 0}$ & $\mathbf{8 5 . 7 \%}$ & $\mathbf{3 2}$ & $\mathbf{9 1 . 4 \%}$ & \\
\hline
\end{tabular}

2-Postoperative pain: The pain levels measured 2 hours postoperatively at the nasal side packed with CMCF ranged from 1 to 5 (mean 1.96), 6 hours ranged from 1-4 (mean 1.7), 12 hours ranged from 1-3 (mean 1.29), 24 hours ranged from 0-2 (mean 0.98) and removal ranged from 0-1 (mean 0.35), While the pain levels 2 hours postoperatively at the other nasal side packed with LGM ranged from 1 to 6 (mean 2.99), 6 hours ranged from 25 (mean 2.52), 12 hours ranged from 1-4 (mean 2.16), 24 hours ranged from 1-3 (mean 1.65), and on removal after 48 hours ranged from 1-2 (mean 1.46). This difference was statistically significant $(\mathrm{p}<0.001)$. 
Table (1): Comparison between CMCF and LGM among all cases regarding to pain score in different times

\begin{tabular}{|c|c|c|c|c|c|}
\hline \multirow{2}{*}{ Pain Groups } & \multicolumn{2}{|c|}{ CMCF $(n=35)$} & \multicolumn{2}{|c|}{ LGM $(n=35)$} & \multirow{2}{*}{ p-value } \\
\hline & Mean \pm SD & Range & Mean \pm SD & Range & \\
\hline VAS 2h & $1.96 \pm 0.94$ & $1-5$ & $2.99 \pm 1.19$ & $1-6$ & $<0.001 * *$ \\
\hline VAS 6h & $1.70 \pm 0.86$ & $1-4$ & $2.52 \pm 1.22$ & $2-5$ & $<0.001 * *$ \\
\hline VAS 12h & $1.29 \pm 0.89$ & $1-3$ & $2.16 \pm 1.15$ & $1-4$ & $<0.001 * *$ \\
\hline VAS 24h & $0.98 \pm 0.68$ & $0-2$ & $1.65 \pm 1.35$ & $1-3$ & $<0.001 * *$ \\
\hline Removal 48h & $0.35 \pm 0.18$ & $0-1$ & $1.46 \pm 0.27$ & $1-2$ & $<0.001 * *$ \\
\hline
\end{tabular}

3-Postoperative synchiae: Endoscopic evaluations and follow-up visits in CMCF group revealed synechiae in 2 patients $(5.7 \%)$ at 4 weeks postoperative and in $r$ patients $(\wedge, 7 \%)$ at 8 weeks postoperative. In the LGM group 5 patients $(14.3 \%)$ at 4 weeks postoperative and 9 patients
$(25.7 \%)$ at 8 weeks postoperative developed synchiae. The difference between groups was statistically insignificant $(\mathrm{p}=0.442)$ at the 4 weeks period and statistically significant $(\mathrm{p}=$ 0.032 ) at the 8 weeks period.

Table (2): Comparison between CMCF and LGM among all cases regarding to synechia in different time

\begin{tabular}{|c|c|c|c|c|c|}
\hline \multirow{2}{*}{$\begin{array}{ll}\text { Synechiae } & \text { Groups }\end{array}$} & \multicolumn{2}{|c|}{ CMCF $(n=35)$} & \multicolumn{2}{|c|}{ LGM $(n=35)$} & \multirow{2}{*}{$P$ value } \\
\hline & No & $\%$ & No & $\%$ & \\
\hline $\begin{array}{l}\text { Synechia } 4 \text { weeks } \\
\text { o } \\
1\end{array}$ & $\begin{array}{l}33 \\
2\end{array}$ & $\begin{array}{l}94.3 \% \\
5.7 \%\end{array}$ & $\begin{array}{l}30 \\
5\end{array}$ & $\begin{array}{l}85.7 \% \\
14.3 \%\end{array}$ & $>0.05$ \\
\hline $\begin{array}{l}\text { Synechia } 8 \text { weeks } \\
0 \\
1\end{array}$ & 32 & $\begin{array}{l}91.4 \% \\
\wedge, 7 \%\end{array}$ & $\begin{array}{l}26 \\
9\end{array}$ & $\begin{array}{l}\mathbf{7 4 . 3} \% \\
25.7 \%\end{array}$ & $<0.05$ \\
\hline
\end{tabular}



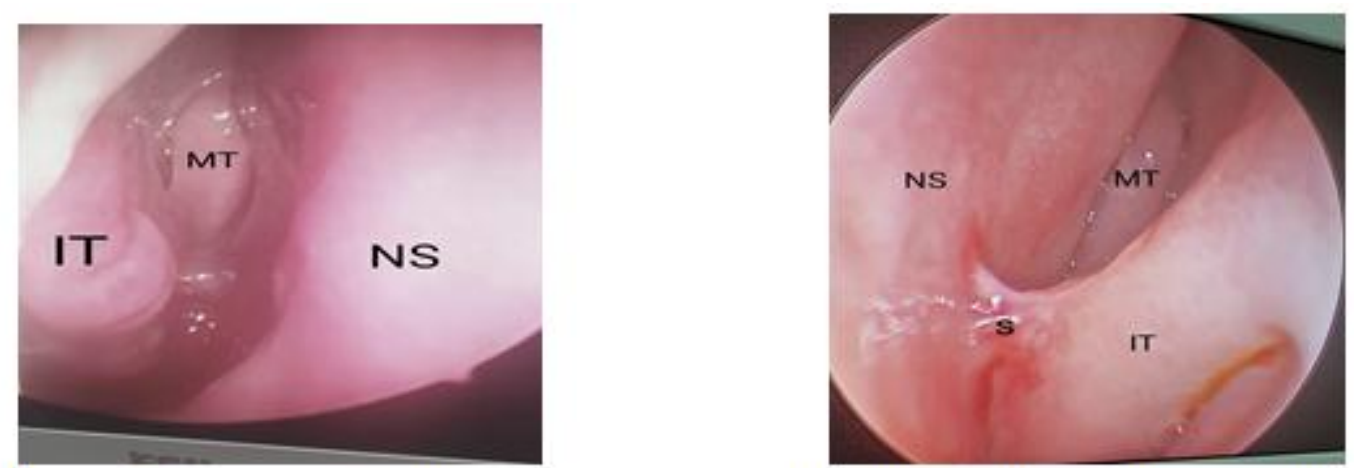

Figure 4. 4 weeks postoperative sinoscopic examination of Rt. nasal cavity that was packed with CMCF revealed no synechiea formation as shown in the Rt. figure, and Lt. nasal cavity that was packed with LGM revealed synechiea between Inf. turbinate and septum as shown in the Lt. figure. IT: inferior turbinate,MT: middle turbinate, NS: nasal septum, S: synechiae.
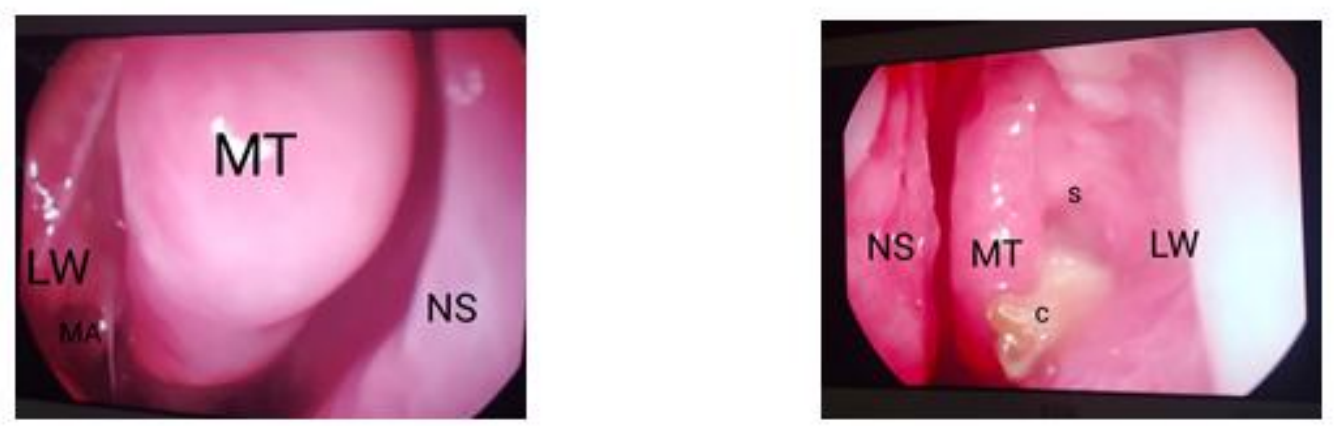

Figure 5. 8 Weeks postoperative sinoscopic examination of middle meatus of Rt. side of the nose that was packed with CMCF revealed patent maxillary antrum with no synechiae as shown in the Rt. figure, while the Lt. side revealed crustation and synechiae formation as shown in the Lt. figure.

C: crusts, LW: lateral wall, MA: maxillary antrum, MT: middle turbinate, NS: nasal septum S: synechiae.

\section{DISCUSSION}

Chronic rhinosinusitis (CRS) is a common disease that affects $10-15 \%$ of the general population (Hamilos, D. L. 2011). Function Endoscopic sinus surgery (FESS) is widely accepted as the intervention of choice for chronic rhinosinusitis (CRS) refractory to medical therapy (Khalid et al., 2009). Nasal packing after functional endoscopic sinus surgery (FESS) is used as a standard procedure, to many different types of packing material has been introduced. They have varied from removable to dissolvable, but an ideal, widely used comfortable packing is still lacking (Valentine et al., 2010).

The removable nasal packs considered the very popular packing used after FESS and nasal surgeries because of their low cost, easily placed and wide availability. They prevent the postoperative bleeding through local pressure on the surgery areas, but patients consider the procedure of pack removal as the most painful and uncomfortable part of sinus and nasal surgery (Shoman et al., 2009). In terms of the patients the removal of the nasal packs after the nasal surgeries is a very painful and scary process. The process of packing 
removal can lead anxiety, fear and stress in patients. The patient may have a relative or friend who had nasal operation before. Because of this experience, the patients may suffer from anxiety and even may be refuse the operation. For this reason, there are many researches in the literature about the issue pointing the patient comfort (Hosemann et al., 2011). Patients expectations of comfort after sinus surgery have increased, so patient's comfort plays an increasingly important role and must be considered when choosing a packing material, even if functional effectiveness remains the primary concern. Considering the risks of nasal packs, some have abandoned nasal packs altogether, leading to the development of new products that do not have the same properties (pressure and support) as formed packs. Biodegradable packs are designed to avoid the disadvantages of removable nasal packs. When applied only to the wound surfaces, they allow the patient to breathe normally, which significantly increases patient comfort (Weber, 2009). CMC foam is vegetable-based polysaccharide foam that actively promotes platelet aggregation upon contact with blood. The dressing placed in a syringe is composed of two grams of carboxymethyl cellulose (CMC) dry fibers and forms a viscous gel when mixed with sterile solution $(20 \mathrm{cc}$ of ringers lactate), the $\mathrm{CMC}$ gels form a viscous dissolvable foam that conforms to the nasal cavities while providing a moist, hydrocolloid physical barrier (Szczygielski et al., 2010). The relatively new, removable nasal packing covered with CMC fibres are effective, easy to use and are more comfortable than traditional tamponades for patients with anterior epistaxis (Soyka et al., 2011).

Much of previous studies divided the patients into groups each group was packed by a single type of nasal packs placed in both nasal cavities, while in the present study we compare between two different nasal packs (CMC foam and LGM) each one placed in one nasal cavity and the other nasal pack placed in the other nasal cavity of the same patient to establish the pain threshold, coagulation factors and healing factors to make more accurate comparison results.

The results of current study found that CMC foam is effective in prevention of postoperative bleeding with very low levels of the pain during the 24 hours after surgery. This confirms results of the following quoted trials of CMC pack (Szczygielski et al., 2010, Okushi et al., 2012, Edizer et al., 2012, Cho et al., 2013, Al-Shaikh et al., 2014 and Orlandi et al., 2016). Kamoun et al. (2017) determined the efficacy of an absorbable hyaluronic acid nasal dressing in reducing synechia formation after FESS relative to nonabsorbable packing. They did not find a statistically significant difference between the absorbable and non-absorbable dressings. For reducing synchiae, our study demonstrated that the occurrence of synechia formations after use of CMC was relatively lower than the occurrence after non absorbable latex gloved merocel. Our observations support the results of Szczygielski et al. (2010), but differ from those of Valentine et al. (2010) who noted no postoperative synechia formation with Sinu-Knit packing (CMC derivative). 


\section{COMPARATIVE STUDY BETWEEN NASAL PACKING WITH CARBOXY...}

\section{CONCLUSION}

Absorbable nasal pack carboxymethyl cellulose was safe and can be considered a valid alternative to standard nasal dressings. It was well-tolerated, easily placed and can be placed locally on the bleeding surface only. It was easily removed by nasal wash and suction seemd to decrease synechia formation and promote postoperative sinonasal healing. It was associated with very low levels of localised pain and postoperative bleeding. Although latex gloved merocel associated with lower level of pain than nongloved merocel but still associated with postoperative pain and more synechiae formation .CMC gel can be recommended after nasal and functional sinus surgery.

\section{REFERENCES}

1. Al-Shaikh S., Muddaiah A. and Lee R.J. (2014): Oxidised cellulose powder for haemostasis following sinus surgery: a pilot randomised trial. J Laryngol Otol., 128 (8): 709-13.

2. Cho K.S., Shin S.K. and Lee JH. (2013): The efficacy of Cutanplast nasal packing after endoscopic sinus surgery: A prospective, randomized, controlled trial. Laryngoscope, 123 (3): 564-8.

3. Edizer, D. T., Yiğit, Ö., Onur, F., and Alkan, Z. (2012): Nasal septal packing: which one?. European Archives of Oto-RhinoLaryngology, 269(7): 1777-1781.

4. Hajosch, R., Suckfuell, M., Oesser, S., Ahlers, M., Flechsenhar, K., and Schlosshauer, B. (2010): A novel gelatin sponge for accelerated hemostasis. Journal of Biomedical Materials Research Part B: Applied Biomaterials, 94(2): 372-379.

5. Hamilos, D. L. (2011): Chronic rhinosinusitis: Epidemiology and medical management. Journal of Allergy and Clinical Immunology, 128(4), 693-707.
6. Hosemann W. and Draf C. (2013): Danger points, complications and medico-legal aspects in endoscopic sinus surgery. GMS Curr Top Otorhinolaryngol. Head and Neck Surg., 12:Doc06.

7. Hosemann W, Loew TH, Forster M, Kuhnel T, Beule AG. (2011): Perioperative pain and anxiety in endoscopic sinus surgery. Otorhinolaryngol., 90(8):476-80.

8. Kamoun, E. A., Kenawy, E. R. S., and Chen, X. (2017): A review on polymeric hydrogel membranes for wound dressing applications: PVA-based hydrogel dressings. Journal of advanced research, 8(3): 217-233.

9. Khalid, A. N., Mace, J and Smith, T. L. (2009): Outcomes of sinus surgery in adults with cystic fibrosis. Otolaryngology-Head and Neck Surgery, 141(3): 358-363.

10. Massey C. J. and Singh A. (2017): Advances in Absorbable Biomaterials and Nasal Packing. Otolaryngol. Clin N. Am., 50(3):545-563.

11. Mira, J. J., Tomás, O., Virtudes-Pérez, M., Nebot, C. and Rodríguez-Marín, J. (2009): Predictors of patient satisfaction in surgery. Surgery, 145(5): 536-541.

12. Murr, A. H., Smith, T. L., Hwang, P. H., Bhattacharyya, N., Lanier, B. J., Stambaugh, J. W., and Mugglin, A. S. (2011): Safety and efficacy of a novel bioabsorbable, steroid- eluting sinus stent. In International Forum of Allergy \& Rhinology, 1(1):23-32.

13. Okushi T., Yoshikawa M. and Otori N. (2012): Evaluation of symptoms and QOL with calcium alginate versus chitin-coated gauze for middle meatus packing after endoscopic sinus surgery. Auris Nasus Larynx, 39: 31-37.

14. Orlandi, R. R., Kingdom, T. T., Hwang, P. H., Smith, T. L., Alt, J. A., Baroody, F. M. and Chiu, A. (2016): International consensus statement on allergy and rhinology: rhinosinusitis. In International Forum of Allergy \& Rhinology, 6(S1): S22-S209.

15. Shoman N, Gheriani $H$ and Flamer $D$ (2009): Prospective, double-blind, randomized trial evaluating patient satisfaction, bleeding, 
and wound healing using biodegradable synthetic polyurethane foam (NasoPore) as a middle meatal spacer in functional endoscopic sinus surgery. J. Otolaryngol. Head Neck Surg., 38: 112-118.

16. Soyka, M. B., Nikolaou, G., Rufibach, K., and Holzmann, D. (2011): On the effectiveness of treatment options in epistaxis: an analysis of 678 interventions. Rhinology, 49(4): 474-478.

17. Szczygielski K, Rapiejko $P$ and Wojdas $A$ (2010): Use of CMC foam sinus dressing in FESS. Eur. Arch. Otorhinolaryngol., 267 (4): 537-40.
18. Valentine, R., Athanasiadis, T., Moratti, S., Hanton, L., Robinson, S. and Wormald, $\mathbf{P}$. J. (2010): The efficacy of a novel chitosan gel on hemostasis and wound healing after endoscopic sinus surgery. American Journal of Rhinology \& Allergy, 24(1): 70-75.

19. Verim A.seneldir L. and Naiboglu B. (2014): Nasal Packing in Surgical Outcome for CRS with polyposis. Laryngoscope, 124: 1529-1535.

20. Weber RK. (2009): Nasal packing and stenting GMS Current Topics in Otorhinolaryngology - Head and Neck Surgery, 8:1865-1011. 
در اسة مقارنة بين حشو الأنف بمادة الكاربوكسى ميثيل

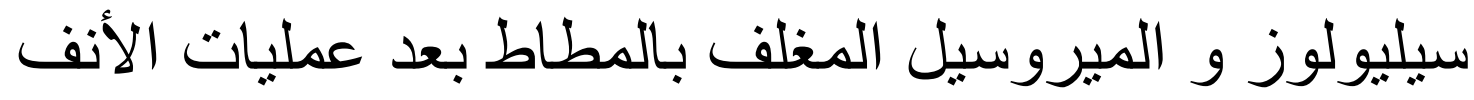
و الجيوب الأنفية الوظيفية بالمنظار

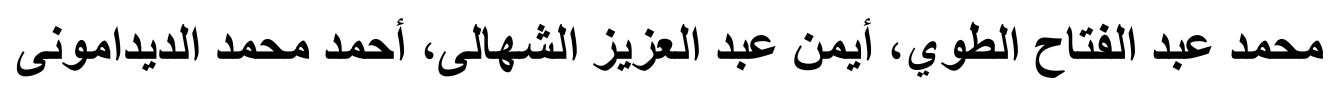

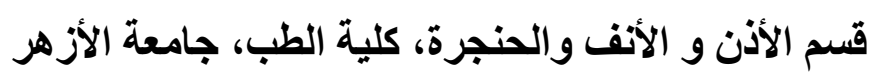

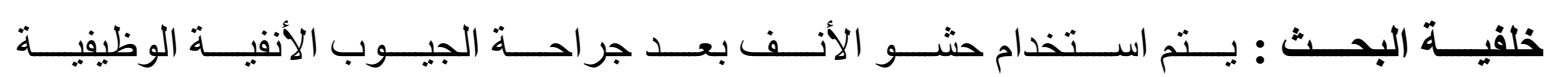

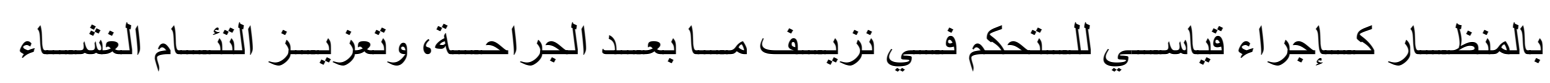

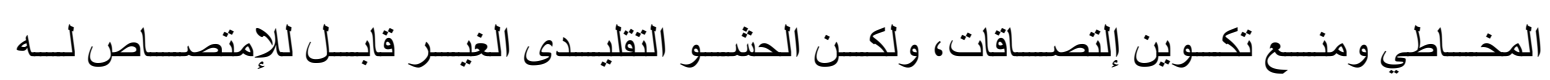

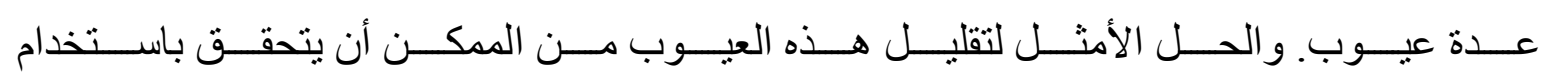
حشو أنفى جديد قابل للنحلل.

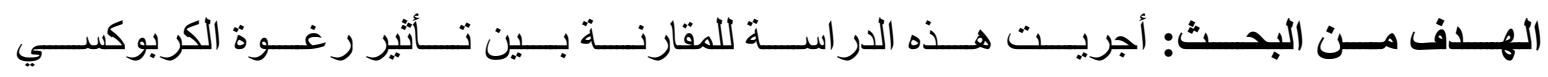

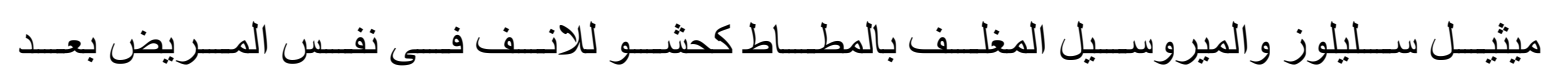

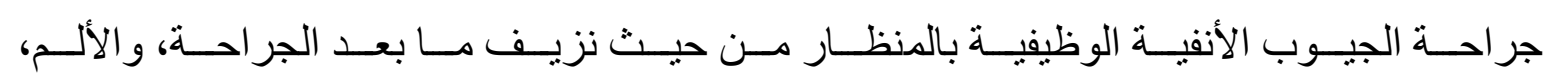

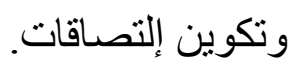

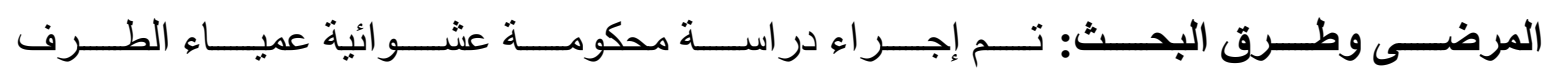

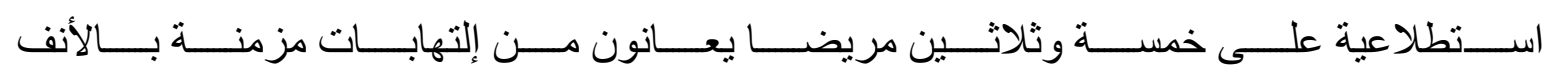

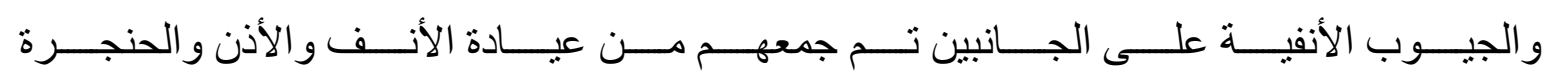

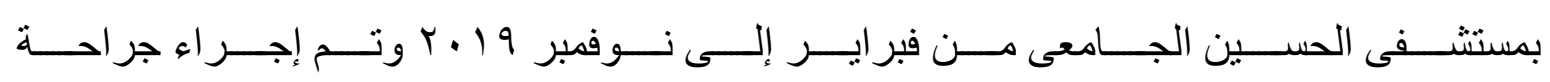

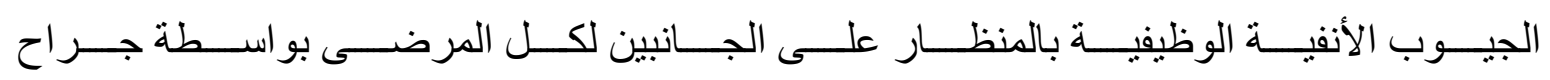

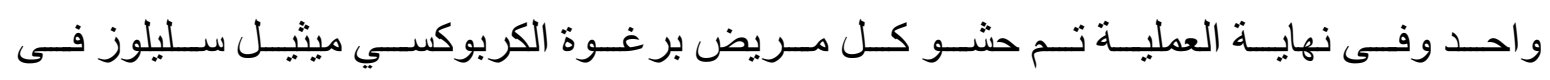

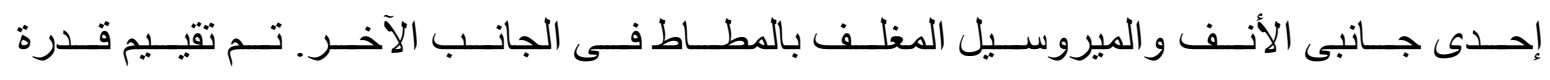

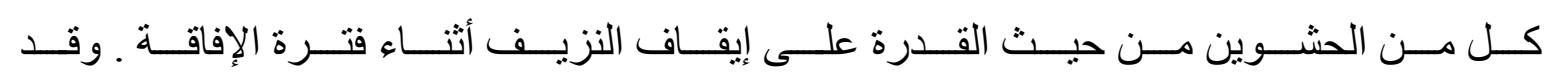

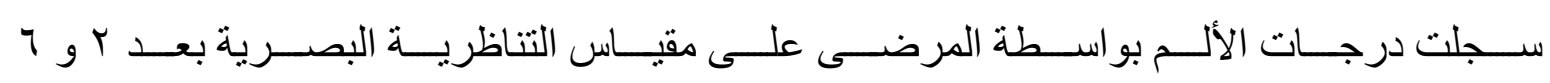

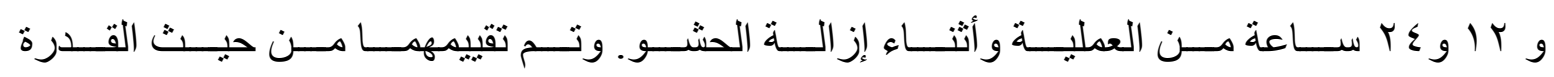
على منع تكوين إلتصاقات بعد ؛ و ^ أسابيع من العطلية. 


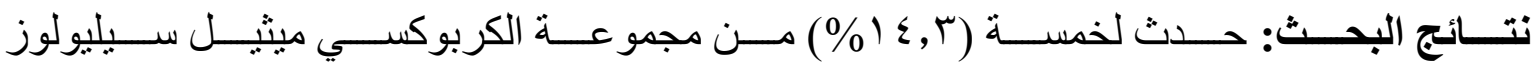

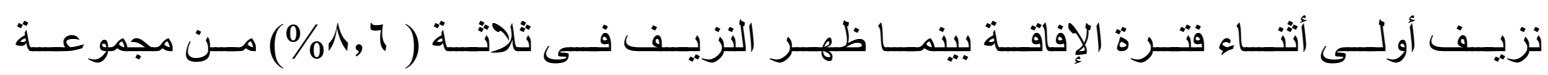

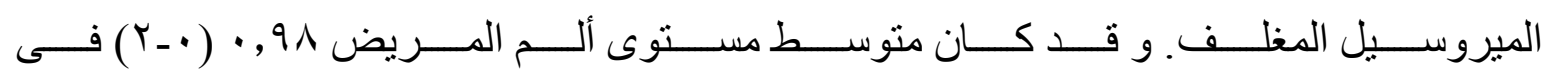

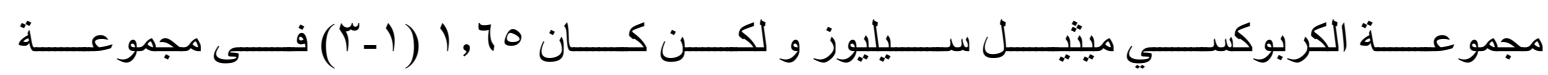

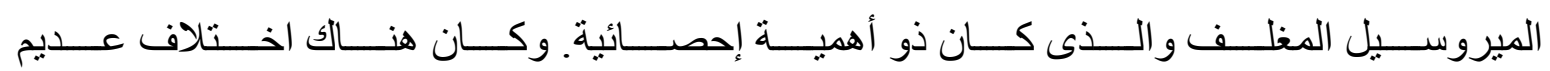

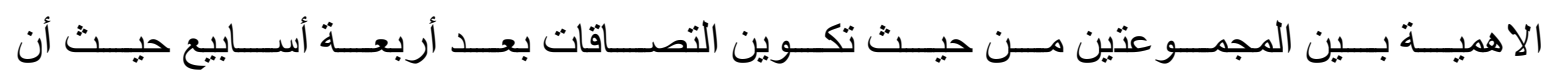

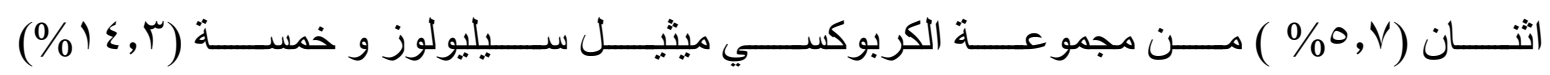

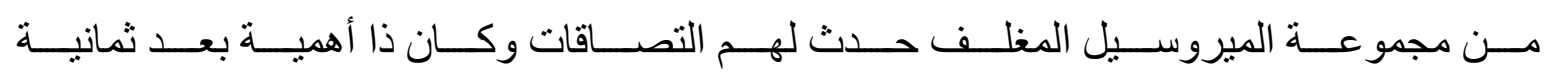

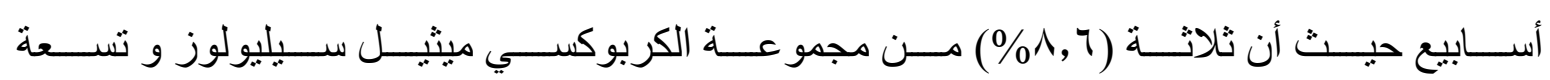
(\% من مجمو عة الميروسيل المغلف حدث لهم التصاقات.

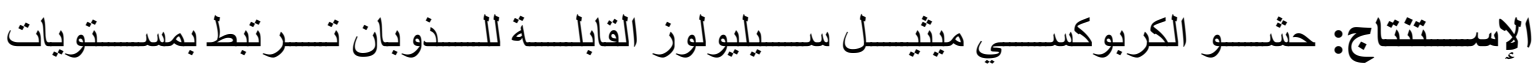

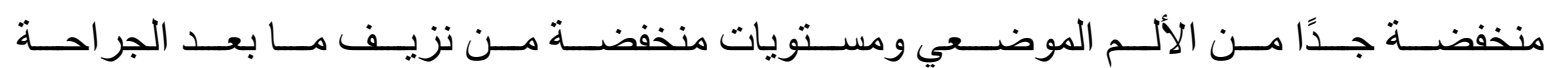
وتكوين إلتصاقات. 